\title{
Enriqueta Quiroz y Diana Bonnett (coordinadoras), Condiciones de vida y de trabajo en la América colonial. Legislación, prácticas laborales y sistemas salariales, Bogotá, Universidad de los Andes, 2009, 326 páginas
}

\author{
Lilia Paola Martínez Meléndez* \\ lmartinezm@unicartagena.edu.co
}

Quien alguno no quisiere trabajar, tampoco comaํ․

El trabajo es una actividad fundamental para el desarrollo de la vida de todo ser humano, social y naturalmente está íntimamente relacionado con la corporalidad y la espiritualidad del hombre. Desde las escrituras bíblicas, hasta los manifiestos del comunismo se hace referencia al trabajo, recalcando la importancia de su práctica tanto para el hombre como ser individual, como para la sociedad en su conjunto. Para las sociedades occidentales tradicionales el trabajo es la base del sostenimiento del individuo, en consecuencia, si tenemos en cuenta las concepciones modernas de trabajo, es a través de él que el individuo sobrevive y logra el desarrollo, el trabajo es a su vez una de las maneras en las que el hombre se integra de directa o indirectamente al sistema capitalista. El trabajo en suma, es inherente al ser humano que este inserto dentro de los parámetros convencionales de la sociedad.

El hombre se convierte con el trabajo en una pieza más del engranaje de la sociedad, en tal sentido, participa inconscientemente dentro de las lógicas que ella impone. Es casi un hecho premeditado que todo hombre desde el momento de su nacimiento esté destinado al trabajo, ya sea intelectual, manual o físico; "todo individuo, que disfrute de una resistencia física suficiente, es apto para trabajar, tienen los medios corporales y mentales necesarios, y si no lo hace es más bien debido a

\footnotetext{
* Estudiante de VII semestre Programa de Historia Universidad de Cartagena.

${ }^{1}$ Segunda epístola del apóstol San Pablo a los tesalonicenses 3:10
}

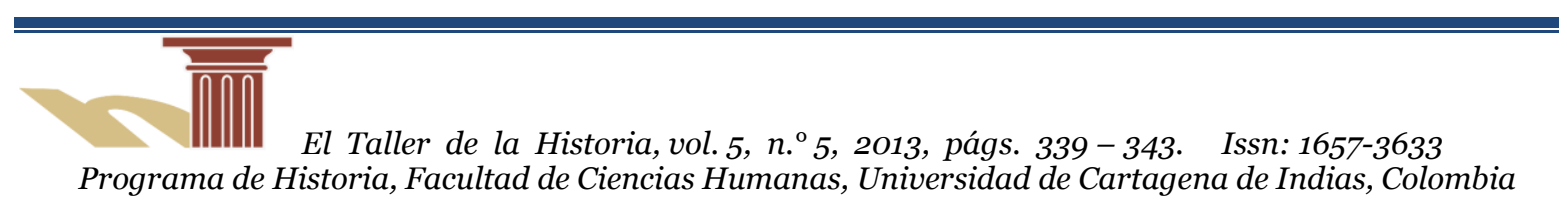


circunstancias económicas y sociales que a la voluntad de evitarlo"2. El trabajo, pues, se convierte en una convención humana más.

Con lo anterior solo se quería ahondar en la trascendencia de la actividad laboral para el ser humano, y por tanto, la importancia de su estudio, ya sea desde la perspectiva histórica o desde cualquier otra ciencia social. Analizar históricamente el trabajo permite comprender las lógicas que se han creado a través del tiempo en torno a esta actividad. Para este caso, analizaremos uno de los estudios que se han centrado en el estudio del trabajo desde la perspectiva histórica, reseñaremos el libro "Condiciones de vida y de trabajo en la América colonial. Legislación, prácticas laborales y sistemas salariales" compilado por Enriqueta Quiroz y Diana Bonnett. Este libro editado por la casa editorial de la Universidad de los Andes es un conjunto de ensayos que a pesar de ser investigaciones aparentemente aisladas geográficamente, presentan un núcleo en común, analizar históricamente las lógicas laborales de la América hispano-lusitana durante el periodo colonial.

El libro se propone entrelazar los enfoques económicos e históricos, con las condiciones de vida de los trabajadores. Realizando análisis de los sistemas salariales, la organización de estructuras laborales o las normativas para el trabajo, los distintos autores que escriben en la publicación, trenzan uno a uno cada uno de estos aspectos para lograr como resultado final un estudio diversificado, en donde el trabajador puede observarse dentro de múltiples facetas, al igual que logra personificarse en distintos actores sociales como los artesanos, los esclavos, el trabajador libre o los indígenas. Además hacen aparición de multiplicidad de escenarios, el trabajo es estudiado en la ciudad, la mina o la plantación agrícola. Lo cual hace que el libro se convierta en material de consulta para quienes estén interesados en los estudios de la historia de la sociedad colonial americana colonial, los estudios del mundo del trabajo o los estudios microeconómicos.

A través de la historia del mundo del trabajo, se llega a comprender los aspectos de la vida de los habitantes de una época, puesto que determina muchas de las características de una sociedad. De las lógicas laborales se puede desglosar muchos aspectos de la sociedad, como el nivel y las condiciones de vida, el desarrollo de la vida como tal, la vida cotidiana, entendiendo que el trabajo hace parte de la cotidianidad de las personas. En el libro se invita a ver las realidades micro de las sociedades hispanas coloniales a partir de los estudios económicos y sociales; esta

\footnotetext{
${ }^{2}$ Robert Fossier, El trabajo en la Edad Media, Barcelona, Ed. Crítica, 200o, p. 7.
} 
es la esencia del libro, el cual hace un recorrido por algunos casos de la América hispana estudiando aspectos del mundo laboral. Espacialmente es un intento por abarcar todos los puntos de la del imperio español y portugués. Aparecen estudios de la Nueva Granada, Brasil, Nueva España, Perú, Castilla, Cataluña y Chile.

Metodológicamente cada uno de los capítulos esta permeado por los análisis realizados desde la historia social, la historia económica, la sociología histórica y la historia comparativa. Estructuralmente libro lo transversaliza las variables que su título menciona: condiciones de vida, prácticas laborales y sistemas salariales; en este sentido, cada uno de los artículos que componen el libro toca alguno de estos aspectos. El primero de los capítulos, escrito por Enriqueta Quiroz, es un análisis historiográfico de las líneas de investigación sobre el mundo del trabajo, como texto inaugural, intenta esbozar los puntos clave del libro, los problemas abordados y las discusiones que son propuestas en él, además de realizar una micro reseñar cada uno de los artículos que lo componen.

El segundo capítulo es una propuesta para la aproximación de las lógicas del trabajo indígena en la Nueva Granada entre los siglos XVII y XVIII. En este artículo de Diana Bonnett se plantean los mecanismos con los cuales se incorpora la mano de obra indígena al sistema económico colonial, así como la configuración y construcción de las instituciones que recorrieron la vida colonial (p.23), y la legislación de dicho sistema laboral. Argumenta que en torno a la actividad laboral se crearon significados y representaciones e imaginarios colectivos por lo general adoptados desde las concepciones europeas, como por ejemplo el desdén por las actividades que requería de una actividad manual o física.

El tercer artículo es un análisis del mundo laboral del Brasil del siglo XVIII, es una síntesis de las características de la economía agroexportadora y mineroexportadora del Brasil colonial, en la cual el trabajo era fundamental para el desarrollo de esta economía. Pretende discutir las formas de organización del trabajo libre, esclavo e indígena. Eni de Mesquita Samara e Ismenia Tupy no solo tratan el tema del trabajo dentro de la plantación o la mina, sino también en los ámbitos urbanos y domésticos. Durante su análisis, estudian las relaciones que se generaban entre el amo o gran propietario y el trabajador, los cuales eran vínculos de solidaridad y relaciones intrínsecas paternalistas.

Los estudios históricos comparativos hacen su aparición en el libro en el cuarto y quinto capítulo. Por un lado, el texto escrito por Manuel Miño, es un estudio en paralelo entre los estados del mundo del trabajo de los virreinatos de la 
Nueva España y del Perú. Analiza el desarrollo de la legislación del trabajo artesanal novohispano y peruano. Plantea el tránsito de la economía de una sociedad rural a una sociedad mercantil, o de una sociedad delineada por el trabajo en la mita a una sociedad de trabajo libre. Dicho transito fue imposible, propone que este proceso estuvo determinado por las concepciones indígenas preexistentes a la conquista lo que impidieron que muchas de los cambios que se querían impulsar no se realizaran por completo.

Por otro lado, el segundo artículo que intenta plantear la metodología comparativa para las investigaciones históricas es texto "Hacia una historia comparada: producción textil y en España y la Hispanoamérica colonial, siglos XVI-XVIII". Con planteamientos económicos un poco más marcados que en el resto de los artículos del libro, el ensayo describe desde la perspectiva del tiempo largo, los ciclos económicos que se formaron en torno a la producción textil en Hispanoamérica, para luego compararlos con los ciclos que se tejieron en España. Su objetivo es "analizar y demostrar como el desarrollo en materia de producción textil en la península Ibérica y en las Indias Occidentales tuvo propósitos diferentes en cada región, generando en ambos continentes coyunturas en paralelo o encontradas" (p. 109), que se complementaban una a la otra.

El sexto capítulo se instala en una región particular del continente americano, la península del Yucatán. Este lugar carecía de metales preciosos o productos agrícolas de consideración, no obstante, eran cultivados algodón, cera, maderas finas o tintes vegetales; la principal riqueza de este territorio la constituía la mano de obra indígena. Fue por medio de instituciones como la encomienda que los colonizadores lograron controlar y explotar el recurso humano, que era la única fuente de riqueza que representaba esta zona habitaba por antiguos pueblos mayas.

El trabajo en la mina, al igual que la labor agrícola requiere de una considerable mano de obra, este escenario laboral tiende a poseer las peores condiciones para su realización. El artículo escrito por María Concepción Gaviria intenta analizar las condiciones de los trabajadores mineros en las minas ubicadas en dos regiones del territorio español, Charcas en el virreinato del Rio de la Plata y Michoacán en Nueva España. Por lo general la mano de obra que era usada para el trabajo en la mina eran indígenas sometidos y obligados a realizar esta labor a través de instituciones coloniales como el repartimiento y la mita. 
El último ensayo del libro, se desprende un poco de los escenarios del artículo anterior para concentrarse en el trabajo urbano. Nuevamente Enriqueta Quiroz escribe y publica un texto que estudia los salarios y las condiciones de vida de los trabajadores durante la construcción de la Casa de la Moneda de Santiago de Chile a finales del siglo XVIII. Plantea que el estudio de los salarios le permite a los historiadores tener bases para conocer cuales eras las condiciones de vida de los trabajadores (p. 211). Analiza el tipo de labor realizada y la remuneración dada por cada uno de los actores de la construcción, ya sean arquitectos, albañiles, peones, maestrantes, carpinteros, mayordomos, sobrestantes barreteros o mezcleros. Cada uno de estos sujetos realizaba una función en la obra, y todos se relacionaban en una relación jerárquica piramidal, con relaciones de mando verticales. Describe un ambiente en donde solo los empleados que obtenían una remuneración considerable lograrían tener los medios justos para su subsistencia, en tanto otros solo su salario les era poco para vivir.

En general esta compilación es un estudio sistemático que solo deja por fuera algunas regiones del continente que merecen ser estudiadas, como el trabajo en los puertos o todo las labores que se crean en torno a la vida marítima. Cada uno de los artículos intenta dibujar la parte humana del trabajo, es un aporte a la historiografía de la sociedad colonial americana. Con esto no aseguramos que se hayan agotado los problemas o los recursos para el estudio del mundo laboral, como en toda investigación histórica son más las preguntas que quedan abiertas que las que se logran resolver. 